\title{
Absent Bilateral Upper Limb Pulses in Middle Age Male? Takayasu Arteritis
}

\author{
Somika Agarwal ${ }^{1}$, Sapna Gupta ${ }^{1}$, Divya Vijay ${ }^{1}$
}

\section{Abstract}

Takayasu arteritis also termed as pulseless disease is a rare and chronic inflammatory arteritis of large vessels. It is manifested mainly in young age group between 10-40 years with a female predominance. Anesthetic management of these patients is challenging in view of fluctuation in blood pressure, intimal fibrosis and stenosis of major blood vessels and multiorgan involvement. Here we present a case of 55 year old male patient with bilateral absent upper limb pulses posted for emergency surgery in view of gall bladder perforation that was successfully managed under general anesthesia.

Keywords: Takayasu; Chronic; Inflammatory.

\section{Introduction}

Takayasu arteritis is a chronic, systemic and inflammatory disease. It is a rare disease of unknown etiology in females under 40 years of age [1]. It is a granulomatous and inflammatory disease of aorta and its main branches. Patients can present with pain and numbness of limbs due to poor blood supply, dizziness, chest pain and abdominal pain. The anaesthetic management of such patients can be complicated due to fluctuation in blood pressure, aneurysms of aorta and its main branches, increased chances of myocardial infarction, stroke, heart failure and transient ischemic attack [2]. Here we present a case of 55 year old asymptomatic male patient with absent bilateral upper limb pulses who was posted for emergency surgery in view of gall bladder perforation.

\section{Case Report}

A 55 year old male patient was posted for emergency open cholecystectomy in view of gall bladder perforation.

Preoperatively patient was conscious, cooperative and oriented. On general physical examination bilateral radial and brachial artery pulsations could not be palpated. Right axillary and internal carotid artery pulsations were feeble. In lower limbs, bilateral dorsalis pedis artery pulsations were palpable. Blood pressure in right upper limb was $80 / 50 \mathrm{~mm} \mathrm{Hg}$ and in left upper limb it was $92 / 54 \mathrm{~mm} \mathrm{Hg}$.

Blood pressure in right and left lower limb at the calf region was $150 / 92 \mathrm{~mm} \mathrm{Hg}$. Chest radiography and 12 lead ECG were within normal limits. All blood investigations including complete blood count, renal function test and urine examination were within normal limits.

With the above findings we suspected this patient to have Takayasu arteritis although this is an uncommon presentation in this age group. Patient was taken up without any further evaluation since it was an emergency procedure.

Informed high risk consent was taken. Right subcostal incision was made for gall bladder surgery. Intraoperatively all standard monitoring was done in the operation theatre. The BP cuff was applied in the right lower limb over the calf muscles. An $18 \mathrm{G}$ intravenous line was secured in the left upper limb and bolus of ringer lactate was started. Right sided erector spinae plane (ESP) block was performed at $\mathrm{T} 7$ level in the sitting position using $20 \mathrm{ml}$ of $0.25 \%$ bupivacaine under ultrasonography (USG) guidance with all aseptic precautions. Expert personnel was available to give ESP block within a few minutes whereas putting a thoracic epidural would have taken time. It allowed us to have a selective area under anaesthesia since only right sided ESP block was given.

Patient was given injection midazolam $1 \mathrm{mg}$ and fentanyl 100 ug intravenously. $10 \%$ lignocaine spray was used to reduce stress response to laryngoscopy.

Induction was done with etomidate $16 \mathrm{mg}$ i.v and vecuronium $4 \mathrm{mg}$. After confirming bag and mask ventilation, patient was intubated with endotracheal tube $8.5 \mathrm{~mm}$ internal diameter using C-MAC video-laryngoscope. After confirming bilateral air entry and end tidal $\mathrm{CO}_{2}$ tube was fixed at $22 \mathrm{~cm}$. Patient was put on VCV mode of mechanical ventilation with oxygen and nitrous oxide at a ratio of 50:50.

Intra-operative anaesthesia was maintained with continuous infusion of inj propofol at the rate of $15 \mathrm{ml} /$ hour by an infusion pump and vecuronium $1 \mathrm{mg}$ as and when required. Analgesia was maintained with inj paracetamol 1 gram and diclofenac $75 \mathrm{mg}$ IV infusion. All vitals were well maintained throughout the intra-operative period.

Challenges in monitoring intraoperatively: invasive arterial monitoring is required in such patients. However it was difficult for us

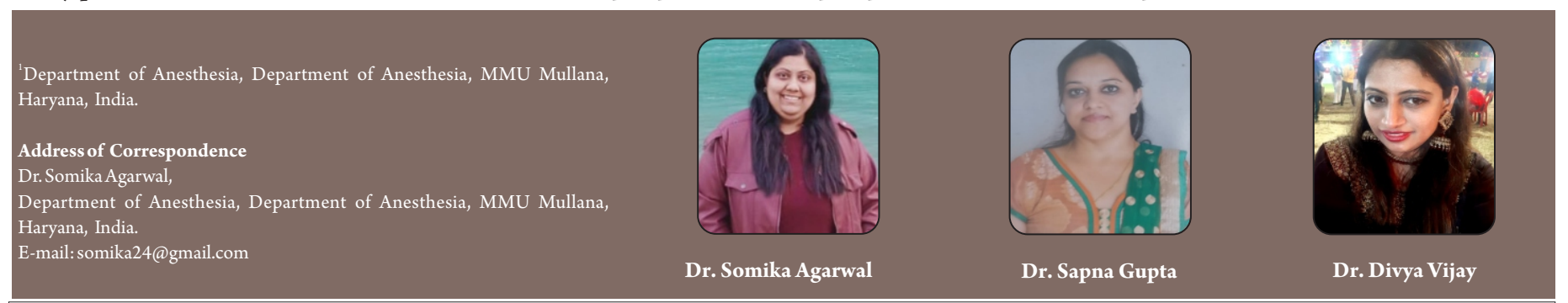

(C) 2020 by Journal of Anaesthesia and Critical Care Case Reports| Available on www.jaccr.com | DOI: 10.13107/jaccr.2020.v06i03.161

This is an Open Access article distributed under the terms of the Creative Commons Attribution Non-Commercial License (http://creativecommons.org/licenses/by-nc/3.0)

which permits unrestricted non-commercial use, distribution, and reproduction in any medium, provided the original work is properly cited.

25 | Journal of Anaesthesia and Critical Care Case Reports | Volume 6; Issue 3 | September-December 2020 | Page 25-26 


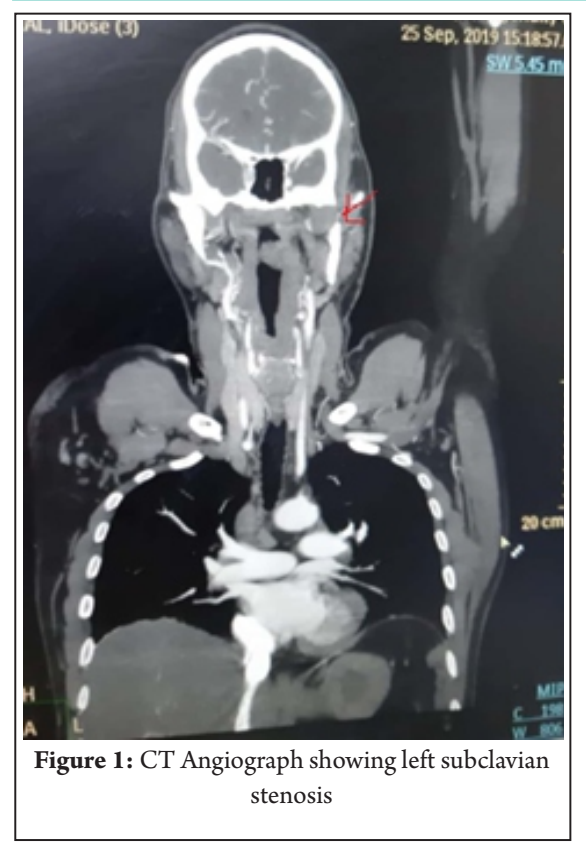

to take an arterial line because peripheral pulsations were absent bilaterally in our patient and since the case was an emergency for us, we preferred to save time.

Surgery lasted for 45 minutes. Patient was reversed using myopyrolate $2.5 \mathrm{mg}$. After thorough suctioning, patient was extubated and shifted to post-operative ward in stable condition.

\section{Post-operative Period}

No motor blockade was there post operatively. Pain relief lasted for 12-13 hours. Side effects of local anaesthetics were also avoided with preferred ESP over epidural analgesia.

On day 3 patient was further investigated. Bilateral upper limb Doppler showed calcified plaques in left and right common carotid artery bifurcation. Bilateral upper limb arteries (subclavian, axillary, brachial, radial, ulnar) showed monophasic to parvus tardus waveform. 2D echo was within normal limits. CT angiography showed focal areas of wall calcification in the arch of aorta, ascending and descending aorta. There was narrowing at the origin of left subclavian artery which was obliterating the lumen $>50 \%$. Right subclavian was also stenosed $>50 \%$ at its origin confirming our provisional diagnosis of Takayasu arteritis. Renal arteries were not stenosed.

\section{Discussion}

Main feature of Takayasu arteritis is the stenosis of major vessels which involve aorta and its proximal branches. It results in the narrowing of the lumen of vessels leading to ischemia and absence of pulses distal to the site of stenosis, therefore termed as "pulseless disease". It has a female predominance with male to female ratio of 1:93 and presents before the age of 40 years. Our patient had type III Takayasu arteritis. Complications associated with this disease are stroke, multiple vessel occlusion, hypertension, pulmonary artery disease, pulmonary artery hypertension, renal artery stenosis and ankylosing spondylitis. Differential diagnosis includes large vessel vasculitis, inflammatory aortitis, coarctation of aorta and Marfan syndrome.

In this case our main aim was to maintain mean arterial pressure, cerebral perfusion pressure, reduce stress response and fluctuation in vitals. Most of the cases reported earlier had used regional anaesthesia successfully in patients with Takayasu, but there are very few case reports on the implementation of general anaesthesia in patients with suspected Takayasu arteritis for emergency surgery. General anaesthesia has its own disadvantages over regional anaesthesia as it can lead to fluctuation in blood pressure both hypotension and hypertension. Our main emphasis was on maintenance of stable hemodynamics in this patient. For ablation of stress response to laryngoscopy we used 10\% lignocaine local spray that worked effectively. To prevent the stress response to pain we used multimodal analgesia technique including preoperative erector spinae plane block4 which was also very effective. Both intravenous and inhalational induction can be done in such patients. We used etomidate in our patient as inducing agent and depth of anaesthesia was maintained using continuous propofol infusion. Yoshida $\mathrm{M}$ et al had used midazolam with fentanyl for induction [5] and Thorburn $\mathrm{M}$ et al [6] used fentanyl, etomidate and halothane. Gupta $\mathrm{R}$ et al [7] used total intravenous anaesthesia for mandibular plating. Other main concern in these patients is reduction in cerebral perfusion during neck extension while doing laryngoscopy. Supraglottic airway devices can be used to prevent this [8]. In our patient we used C-MAC videolaryngoscope. Shrestha GS et al have used epidural anaesthesia in such patients for elective open cholecystectomy [9]. Regional anaesthesia has advantages in terms of awake and conscious patient and less chances of hemodynamic variation specially with epidural which provides gradual onset of sensory, motor and sympathetic blockade. In our patient we used general anaesthesia since it was an emergency surgery for gall bladder perforation.

\section{Conclusion}

Anaesthetic management in patients with Takayasu arteritis can be challenging. Maintenance of adequate end organ perfusion is vital. Both regional and general anaesthesia can be provided to such patients when administered cautiously and appropriate to the patient condition.

\section{References}

1. Kathirvel S, Chavan S, Arya VK, et al. Anesthetic management of patients with Takayasu's arteritis: a case series and review. Anesth Analg 2001; 93:60-5

2. Poonam S G, Kalpana D H. Anesthetic considerations in a patient with Takayasu's arteritis for cesarean section. Ain-ShamsJAnaesthesiol 2015;8:681-2.

3. Shukla E, Desai A, Malkan N. et al. Nodular scleritis as a presenting feature oftakayasu's arteritis. Indian Jophthalmol.2016;64:312-4

4. Luis-Navarro JC, Seda-Guzmán M, Luis-Moreno C, Chin KJ. Erector spinae plane block in abdominal surgery: case series. Indian J anaesthesia 2018; 62:549

5. Yoshida M, Yamamoto T, Shiiba S, et al. Anesthetic Management of a Patient With Takayasu Arteritis. Anesth Prog. 2016;63:31-3

Conflict of Interest: Nil Source of Support: None

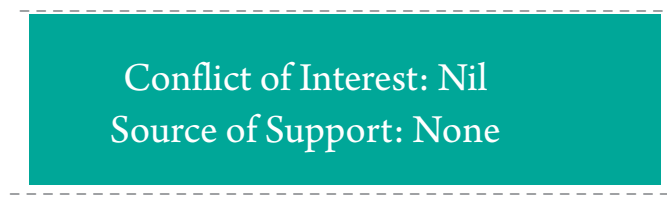

6. Thorburn JR, James FM. Anaesthetic management of Takayasu's arteritis. Anaesthesia, 1986; 41:734-8

7. Gupta R, Singh S, Kaur S. Use of TIVA for Mandibular Plating in a Patient with Takayasu's Disease. JAnaesthesiol Clin Pharmacol.2011;27:133-4.

8. Gaba P, Saxena KN, Dua CK. Takayasu's arteritis: anaestheticimplications and role of ILMA for airway management. Indian J Anaesth 2008;52:858

9. Shrestha, G., Shrestha, N., Shrestha, B., Shrestha, P. Anaesthetic Management of Patients with Takayasu's Arteritis for Open Cholecystectomy: a Report of Two Cases. Journal of Nepal Medical Association 2015; 53: 146-9.

How to Cite this Article

Agarwal S, Gupta S, Vijay D | Absent Bilateral Upper Limb Pulses in Middle Age Male? Takayasu Arteritis | Journal of Anaesthesia and Critical Care Case Reports | SeptemberDecember 2020; 6(3): 25-26. 